\title{
Exploring Sardinian longevity: women fertility and parental transmission of longevity
}

\author{
Graziella Caselli, Rosa Maria Lipsi, Enrica Lapucci and James W. Vaupel*
}

\begin{abstract}
The aims of this study are to analyse the two-way association between women fertility and longevity, and parental transmission of longevity. The wealth of information gathered in the AKeA2 - demographic survey on Sardinian centenarians-have been used by applying Logistic Regression Models. For the association between longevity and fertility, we find evidence that *long livers benefit from factors related to the timing of fertility (in particular the age at birth of the last child) that the literature suggests may foster longevity. Regarding the association with parental transmission, it seems to have significant effects for women but not for men. We always found that a higher birth order decreases the probability of becoming a centenarian. There is a negative effect of a higher father age at birth on the longevity of female offspring. The latter suggests that long-lived women seem to have been favoured both by their own late fertility and young paternal age at the moment of their own procreation.
\end{abstract}

\section{Background and research questions}

The relationship between longevity and fertility has been tackled in various articles (Behr and Small 1997; Westendorp and Kirkwood 1998; Vinogradov 1998; Lycett et al. 2000; Doblhammer 2000; Müller et al. 2002; Doblhammer and Oeppen 2003; Yi and Vaupel 2004; Grundy and Tomassini 2005; Larke and Crews 2006; McArdle et al. 2006). The main results showed that women who live longer seem, on average, to have had fewer children, and at an apparently older age, particularly for their last children.

Kirkwood and Rose $(1991,21)$ referring to the biological "disposable soma theory" assume a trade-off of resources between maintenance (survival) and production. As Westendorp and Kirkwood (1998) demonstrated, when post-menopausal women

\footnotetext{
* Graziella Caselli (correspondence author), Department of Statistical Sciences, Sapienza University of Rome, Italy. Email: graziella.caselli@uniroma1.it

Rosa Maria Lipsi, National Institute of Statistics (ISTAT), Italy.

Enrica Lapucci, Sapienza University of Rome, Department of Statistical Sciences, Italy.

James W. Vaupel, Max Planck Institute for Demographic Research, Germany.
}

DOI: 10.1553/populationyearbook2013s247 
(aged 60 years and over) were included in the analysis, female longevity was negatively correlated with number of progeny and positively correlated with age at first childbirth. The authors emphasise the importance of analysing the effect of fertility behaviour on longevity in post-reproductive ages.

Evolutionary ageing theory predicts that because ageing is a consequence of a trade-off between longevity and reproduction, the age at which organisms begin to reproduce should be positively correlated with maximum longevity, meaning that the driving selective force in the human lifespan is maximising the period of time during which women can bear children (Hamilton 1966; Charlesworth and Charlesworth 1980; Kirkwood and Rose 1991; Vaupel et al. 1998). In terms of evolutionary fitness, natural selection is expected to favour high fertility, early age at first reproduction and late age at last births. Recently, Doblhammer (2000), used population data from Austria, England and Wales to find a positive relationship between giving birth after age 40 and longevity, which is consistent with the findings of previous studies (Voland and Engel 1986; Snowdon et al. 1989; Perls et al. 1997; Cooper and Sandler 1998; Müller et al. 2002; McHardle et al. 2006). In addition, her results suggest that the longevity advantage of late mothers depends on a reduction in their mortality risk from circulatory diseases, although at the same time their risk of breast cancer is significantly increased (Doblhammer and Vaupel 1999).

Also cultural, socioeconomic and biological factors influence the evolution of human life-history traits and can affect individual fitness in terms of fertility as well as the health and survival prospects of progeny and, consequently, progeny longevity. Thus, we may hypothesise that a relationship between offspring longevity and their parental fertility characteristics exists. In fact, several studies have analysed the inheritance of longevity in relation to parental age at birth (Gavrilov et al. 1995; Gavrilova and Gavrilov 1997a; Westendorp and Kirkwood 2001; Smith et al. 2002; Robine et al. 2003) with different conclusions and with varying levels of significance based on offspring gender (Jung et al. 2003). Analysing French centenarian data, Robine et al. (2003) found no association between parental age at birth and the probability of surviving to age 100. Results from the French-Canadian population (Desjardins and Charbonneau 1990) suggested that this inheritable component may be close to zero, and Westendorp and Kirkwood (2001), analysing historical data for the British aristocracy, also failed to find any maternal age effects on longevity. Smith, Mineau and Sahm $(2007,11)$, referring to the Gavrilov and Gavrilova study (1997b) underline that "heritability estimates were much higher in daughters than in sons at all parental ages". In fact, using data from European aristocracy genealogies, Gavrilov and Gavrilova showed a negative effect of a higher paternal age on the longevity of daughters (Gavrilov and Gavrilova 1997a). Daughters of late-fertile women have no survival benefit. However, Smith et al. (2002) demonstrated significant existing effects for a maternal benefit among female offspring.

As regards longevity and familial transmission, a familial contribution to human longevity is recognised, but the nature and importance of this contribution are largely unknown. While several studies used a genetic explanation (Pearl 1931; Abbott et al. 1974, 1978; Philippe 1978; Crawford and Rogers 1982; Bocquet-Apple and Jakoby 
1990; Herskind et al. 1996; Iachine et al. 1998; Perls et al. 2000; Perls and Terry 2003; Sorkin et al. 2005; Christensen et al. 2006), others refer to familial characteristics (Desjardins and Charbonneau 1990; Cournil et al. 2000; Gravilova and Gravilov 2002; Caselli et al. 2006).

A longstanding puzzle in gerontology and genetics is the gender dependence of human longevity and its inheritance, in particular from mother to daughters (Caruso et al. 2000, 2001; Carru et al 2003; Santoro et al. 2006; Raule et al. 2007; Rose et al. 2007; Capri et al. 2008; Rose et al. 2010; Invidia et al. 2010).

The historical and geographical isolation of the Italian island of Sardinia offers an interesting case study to analyse the association of longevity with both fertility and parental transmission. Sardinia today has 1,637,846 inhabitants (2012-01-01) including 359 centenarians ( 79 men and 280 women), with a ratio of 2.2 centenarians per 10,000 inhabitants (Istat database: http://demoistat.it). "Sardinian centenarians are an exceptionally homogeneous group in terms of socio-occupational status, with the men usually having been either peasants or shepherds, and the women having been housewives, following an age-old tradition handed down from parent to child" (Caselli et al. 2006, 728). It was characterised by the patriarchal structure of the family, by the historical characteristics of high and late fertility and the persisting tendency to postpone marriage and childbearing (Livi Bacci 1977; Zei et al. 1990; Astolfi et al. 2002, 2009) and, last but not least, by an internal area, dubbed 'Blue Zone' (Poulain et al. 2004), with a higher frequency of centenarians (Deiana et al. 1999). The social and cultural background, associated with low mobility in the past (Golini 1967), endogamy and consanguinity (Zei et al. 1986), have produced biological and genetic differentiation across Sardinian areas. The genetic peculiarities of internal areas of Sardinia, such as the high frequency of ancient genetic markers of mitochondrial and $\mathrm{Y}$ chromosomes, might derive from the action of micro-evolutionary forces on isolated populations (Cavalli-Sforza et al. 1994; Zei et al. 2003; Carru et al. 2003; Pes et al. 2004; Astolfi et al. 2009). The consequent genetic makeup is also partially determined by endemic malaria in the past (Modiano et al. 1986; Caglia et al. 1997).

The aims of this paper are to analyse the two-way association between fertility and longevity as well as parental transmission of longevity. In particular, for the first aim our research questions are: is there a protective effect of fertility on maternal survival at advanced ages? Have long-lived women been favoured both by a lower fertility and later childbearing? ${ }^{1}$ We have two research questions for the second aim as well: are parental fertility characteristics related to the longevity of their offspring? And, at the same time, do maternal and paternal longevity favour the longer survival of their offspring?

1 The analyses concerning the first two research questions were presented to the PAA 2013 conference. 
The wealth of information gathered in the $\mathrm{AKeA} 2^{2}$ demographic survey (Caselli et al. 2006) focuses particularly on data collection concerning family genealogies of the Sardinian centenarians and control groups. The characteristics of this survey are wholly original, as were the procedures followed in gathering the information, which entailed for each individual both a control of all the surviving individual certificates in the municipal offices and a qface to face interview questionnaire.

\section{Data and methods}

In the AKeA2 survey, 204 centenarians born between 1890 and 1904 (98 men and 106 women), were selected in 126 municipalities out of the 377 Sardinian municipalities throughout the island. Starting from the information collected by each local municipality on the number of centenarians living in their area, the centenarians and their families were contacted in order to have their consent to be part of our sample. Once the centenarian's consent was obtained, local municipal authorities were contacted again for a list of individuals in order to choose our living controls. In fact, from this list, three matched individuals for each centenarian born in 1905-1910, 1911-1916 and 1918-1925 and thus aged 80-99 years at the beginning of our study in 2004, were selected. A demographic survey was performed that also involved an additional two individuals for each centenarian from the same cohort who had died in their late 60s (60-69 years) and late 70s (70-79 years) (dead controls). All the controls were of the same gender as the centenarian, born in the same municipality, and their day and/or month of birth were as close as possible to that of the centenarian (for more information, see Caselli et al. 2006; Lipsi et al. 2014). Controls bearing the same family name were excluded to avoid excessive consanguinity.

To validate an individual's age, the following documents from civil and population registers (Anagrafe) were examined: birth certificate, marriage certificate(s), the birth certificates of the parents as well as their marriage and death certificates, the birth certificates of all children of the sampled individual, and the birth certificates of the individual's siblings. Complete validation was achieved only when the data had been cross-checked and proven consistent.

By applying the validation procedure, genealogies were reconstructed for 1,145 individuals: 204 centenarians, 581 living controls (we were unable to find 31 suitable controls in a few of the smaller municipalities), and 360 dead controls (in some of

\footnotetext{
2 AKeA2 is the acronym of the survey on Sardinian Centenarians, directed by James Vaupel, Max Planck Institute for Demographic Research, Rostock, Germany (financed by NIA, US, subcontract with Duke University n.03-SC-NIH-1027). The survey follows a previous research project on Sardinian centenarians, named AKeA.

Research Group: Luca Deiana, University of Sassari, Department of Biochemistry; Giovannella Baggio, City Hospital of Padua; Ciriaco Carru, University of Sassari, Department of Biochemistry; Graziella Caselli, Sapienza, University of Rome; Claudio Franceschi, Department of Experimental Pathology, University of Bologna; Gianni Pes, University of Sassari, Department of Biochemistry; Lucia Pozzi, University of Sassari, Department of Economics; James W. Vaupel, Max Planck Institute for Demographic Research, Rostock.
} 
the smaller municipalities 48 appropriate persons could not be identified). For each individual we reconstructed his/her life history as well as the biographies of his/her parents (Caselli et al. 2006).

Full information (100\%) is available for all individuals - centenarians, controls and their parents - regarding year and place of birth, date and place of death (if dead), sex of children and date of death for all dead children. For all other demographic characteristics used in the analysis, completeness ranks from 90\% to 95\% (Lipsi et al. 2013). Among the 20 demographic information items available for the purpose of this study, we considered, for centenarians and controls by gender, the following variables: date of birth; date of death (if applicable); number and dates of birth of their children; number of siblings and their birth order; maternal and paternal dates of birth and death (the variables are listed in the Tables 1-4).

For each individual in our sample we also collected information on his/her educational level and occupation during active life. Unfortunately, it was not possible to include these variables in our analysis due to a great number of missing data and very low variability: as regards education, there is no information for $75.7 \%$ of subjects and more than $20 \%$ were illiterate or had "just few years of school". As regards occupation, $87.7 \%$ of women are housewives and $81.0 \%$ of men are shepherds or farm-workers.

We implemented a logistic regression model in order to investigate both the fertility and longevity association and the parental transmission of longevity (Harell 2001).

Regarding the first aim (i.e. fertility and longevity association), for the reference population we included all women with at least one child $(N=258)$ by comparing those who survived after age 80 with those who died between age 60-69 and 7079 years. We decided not to include childless women in the analysis since we are interested not only in the association between longevity and number of offspring but also in the association between longevity and timing of reproduction (e.g. age at first child and age at last child). Thus, this choice further reduced the sample's size and, consequently, in analysing the association between fertility and longevity, we preferred to define long-lived as women who survive after age 80 . However, as we know that the probability of becoming long-lived women could be influenced by the age at death of both mother and father and, by the birth order of the sampled individuals, our results have been controlled for these variables.

With respect to the familial transmission of longevity, for the reference population we compared those who became centenarians $(N=180$; excluding 24 centenarians without complete information on their parents) with those who died before age 100 $(N=540)$.

In order to analyse the association between longevity and parental characteristics, we considered two dimensions: Parental longevity (age at death of both mother and father) and Parental fertility (parental age at birth, the centenarians and controls' birth order). According to the main literature, the impact on the inheritance of longevity may change according to the offspring's gender. We have therefore presented results for men and women together and separately. 


\section{Results}

\subsection{Longevity and fertility: logistic model results}

Table 1 reports the results of the association between longevity and fertility, considering the two dimensions of fertility: number of children and timing of reproduction. First of all, we found no significant effect of the first dimension (number of children) on the probability of survival after age 80 . Nor does age at first child have any significance. Nevertheless, having the last child at an advanced age shows a protective effect on the mother's survival (mothers who had their last child at age 45 and over show a probability of becoming a long-lived women more than three times higher than mothers who had their last child at 32-44 years). Our results seem to be in line with the hypothesis of a positive association between the presence of young children at old ages of the mother (i.e. late timing of the last birth) and increased longevity. The results are also consistent after controlling by maternal and paternal longevity of sampled individuals. However, it is interesting to note the protective effect of maternal longevity, in particular women having a mother who died at oldest ages are advantaged in terms of life span.

\subsection{Parental transmission of longevity: logistic models results}

The aim of this analysis is to investigate the differences in parental characteristics of centenarians and controls. Table 2 shows results for men and women together. Model 1 presents the association between longevity and parental age at death. Having a father who died at younger ages decreases the probability of becoming a centenarian. However, we have a significant effect only for a father who died between 70-79 years, while the mother's age at death does not seem to be significantly related to longevity, although the OR (less than 1) suggests the same association found for fathers.

In Model 2 we include the dimension of parental fertility, birth order of centenarians and controls, and the number of their siblings. In this model, previous results are confirmed but, with respect to the new dimensions included, only the birth order has a significant effect: being fourth or even higher in the birth order decreases the probability of survival after age 100 .

As regards the role of gender, no significant differences were found. However, if we consider men (Table 3) and women (Table 4) separately, interesting conclusions may be drawn. For men, the results of the two models (Table 3 ) mirror the previous results presented in Table 2, with the exception of father's age at death, which is never significant. Thus, for men it seems there is no association between their own longevity and that of their parents.

For women (Table 4), longevity transmission is found along both the maternal and paternal line. In fact, having both parents dying at 'younger' ages is associated with a lower probability of becoming a centenarian. Regarding the parental age at birth (Model 2), our results found a high paternal age at birth (40 years and over) has a negative effect on offspring longevity. 
Table 1:

Longevity and fertility characteristic: results of logistic regression model.

Women $(N=258)$

\begin{tabular}{|c|c|c|c|c|c|c|}
\hline Characteristics & $\begin{array}{c}\text { Died } \\
\text { 60-79 years } \\
(n=125)\end{array}$ & $\begin{array}{c}\text { Survive } \\
\text { after age } 80 \\
(n=133)\end{array}$ & OR & & \multicolumn{2}{|c|}{$95 \% \mathrm{IC}$} \\
\hline \multicolumn{7}{|l|}{ No. child } \\
\hline $1-4$ & 56 & 43 & 1.00 & & - & - \\
\hline $5-8$ & 46 & 70 & 1.49 & & 0.66 & 3.39 \\
\hline $9+$ & 23 & 20 & 0.63 & & 0.22 & 1.84 \\
\hline \multicolumn{7}{|l|}{ Age at first child } \\
\hline$<=20$ & 13 & 14 & 1.34 & & 0.53 & 3.39 \\
\hline $21-32$ & 91 & 83 & 1.00 & & - & - \\
\hline$>=33$ & 21 & 14 & 0.66 & & 0.23 & 1.86 \\
\hline Missing & 0 & 22 & - & & & \\
\hline \multicolumn{7}{|l|}{ Age at last child } \\
\hline$<=31$ & 20 & 14 & 0.76 & & 0.27 & 2.14 \\
\hline $32-44$ & 97 & 80 & 1.00 & & - & - \\
\hline$>=45$ & 8 & 17 & 3.74 & $* *$ & 1.39 & 10.18 \\
\hline Missing & 0 & 22 & - & & & \\
\hline \multicolumn{7}{|c|}{ Mother's age at death } \\
\hline$<=69$ yrs & 52 & 38 & 0.47 & $* *$ & 0.24 & 0.90 \\
\hline $70-79$ yrs & 34 & 27 & 1.00 & & - & - \\
\hline$>=80 \mathrm{yrs}$ & 36 & 51 & 0.61 & & 0.29 & 1.27 \\
\hline Missing & 3 & 17 & 3.19 & & 0.73 & 13.74 \\
\hline \multicolumn{7}{|c|}{ Father's age at death } \\
\hline$<=69$ yrs & 49 & 55 & 0.96 & & 0.49 & 1.88 \\
\hline $70-79$ yrs & 38 & 24 & 1.00 & & - & - \\
\hline$>=80 \mathrm{yrs}$ & 30 & 42 & 0.56 & & 0.26 & 1.21 \\
\hline Missing & 8 & 12 & 0.51 & & 0.13 & 1.99 \\
\hline \multicolumn{7}{|l|}{ Birth Order } \\
\hline 1 & 29 & 32 & 1.00 & & - & - \\
\hline $2-3$ & 40 & 45 & 0.99 & & 0.47 & 2.08 \\
\hline $4-5$ & 26 & 29 & 0.80 & & 0.39 & 1.68 \\
\hline $6+$ & 30 & 27 & 1.07 & & 0.33 & 3.53 \\
\hline
\end{tabular}

${ }^{* * *} p$-value $<0.001 ;{ }^{* *} p$-value $<0.05 ;{ }^{*} p$-value $<0.1$.

Source: Our elaboration on AKeA2 survey data. 
Table 2:

Parental transmission of longevity: results of logistic regression model.

Men and women $(N=720)$

\begin{tabular}{|c|c|c|c|c|c|c|c|c|c|c|}
\hline \multirow[b]{2}{*}{ Characteristics: } & \multicolumn{2}{|c|}{$\begin{array}{l}\text { Survive after } \\
\text { age } 100\end{array}$} & \multicolumn{4}{|c|}{ Model 1} & \multicolumn{4}{|c|}{ Model 2} \\
\hline & $\begin{array}{c}\text { Not } \\
(n=540)\end{array}$ & $\begin{array}{c}\text { Yes } \\
(n=180)\end{array}$ & OR & & $95 \%$ & $\% \mathrm{IC}$ & OR & & $95 \%$ & $\% \mathrm{IC}$ \\
\hline Male & 266 & 85 & 1.00 & & - & - & 1.00 & & - & - \\
\hline Female & 274 & 95 & 1.08 & & 0.77 & 1.52 & 1.07 & & 0.75 & 1.51 \\
\hline \multicolumn{11}{|c|}{ Mother's age at death } \\
\hline$<=69$ & 193 & 51 & 0.74 & & 0.49 & 1.13 & 0.77 & & 0.50 & 1.17 \\
\hline $70-79$ & 121 & 40 & 0.95 & & 0.60 & 1.51 & 0.94 & & 0.59 & 1.48 \\
\hline $80+$ & 193 & 70 & 1.00 & & - & - & 1.00 & & - & - \\
\hline N.A. & 33 & 19 & 1.60 & & 0.81 & 3.17 & 1.52 & & 0.67 & 3.43 \\
\hline \multicolumn{11}{|c|}{ Father's age at death } \\
\hline$<=69$ & 207 & 70 & 0.89 & & 0.59 & 1.34 & 0.92 & & 0.61 & 1.39 \\
\hline $70-79$ & 135 & 31 & 0.58 & $* *$ & 0.36 & 0.96 & 0.59 & $* *$ & 0.36 & 0.98 \\
\hline $80+$ & 164 & 63 & 1.00 & & - & - & 1.00 & & - & - \\
\hline N.A. & 34 & 16 & 0.98 & & 0.48 & 2.02 & 0.97 & & 0.41 & 2.26 \\
\hline \multicolumn{11}{|c|}{ Mother's age at birth } \\
\hline$<35$ yrs & 387 & 134 & & & & & 1.00 & & - & - \\
\hline$>=35 \mathrm{yrs}$ & 143 & 39 & & & & & 1.17 & & 0.69 & 1.96 \\
\hline N.A. & 10 & 7 & & & & & 1.35 & & 0.37 & 4.88 \\
\hline \multicolumn{11}{|c|}{ Father's age at birth } \\
\hline$<40$ yrs & 327 & 125 & & & & & 1.00 & & - & - \\
\hline$>=40 \mathrm{yrs}$ & 204 & 50 & & & & & 0.69 & & 0.44 & 1.07 \\
\hline N.A. & 9 & 5 & & & & & 0.93 & & 0.22 & 3.81 \\
\hline \multicolumn{11}{|l|}{ Birth order } \\
\hline 1 & 123 & 51 & & & & & 1.00 & & - & - \\
\hline $2-3$ & 172 & 67 & & & & & 0.04 & & 0.61 & 1.49 \\
\hline $4-5$ & 138 & 32 & & & & & 0.59 & ** & 0.31 & 0.98 \\
\hline $6+$ & 107 & 30 & & & & & 0.36 & & 0.33 & 1.43 \\
\hline \multicolumn{11}{|l|}{ No. of siblings } \\
\hline$<=4$ & 136 & 45 & & & & & 1.00 & & - & - \\
\hline $5-6$ & 146 & 45 & & & & & 0.07 & & 0.64 & 1.77 \\
\hline $7-8$ & 149 & 58 & & & & & 0.38 & & 0.87 & 2.48 \\
\hline $9+$ & 109 & 32 & & & & & 0.14 & & 0.61 & 2.17 \\
\hline
\end{tabular}

*** $p$-value $<0.001 ;{ }^{* *} p$-value $<0.05 ;{ }^{*} p$-value $<0.1$.

Source: Our elaboration on AKeA2 survey data. 
Table 3:

Parental transmission of longevity: results of logistic regression model.

$\operatorname{Men}(N=351)$

\begin{tabular}{|c|c|c|c|c|c|c|c|c|}
\hline \multirow[b]{2}{*}{ Characteristics: } & \multicolumn{2}{|c|}{ Survive after age 100} & \multicolumn{3}{|c|}{ Model 1} & \multicolumn{3}{|c|}{ Model 2} \\
\hline & $\begin{array}{c}\text { Not } \\
(n=266)\end{array}$ & $\begin{array}{c}\text { Yes } \\
(n=85)\end{array}$ & OR & \multicolumn{2}{|c|}{$95 \% \mathrm{IC}$} & OR & \multicolumn{2}{|c|}{$95 \% \mathrm{IC}$} \\
\hline & & & & & \multicolumn{4}{|c|}{ Mother's age at death } \\
\hline$<=69$ & 97 & 31 & 1.02 & 0.57 & 1.81 & 1.06 & 0.58 & 1.91 \\
\hline $70-79$ & 49 & 18 & 1.19 & 0.60 & 2.34 & 1.17 & 0.58 & 2.37 \\
\hline $80+$ & 102 & 32 & 1.00 & - & - & 1.00 & - & - \\
\hline N.A. & 18 & 4 & 0.50 & 0.14 & 1.77 & 0.60 & 0.13 & 2.70 \\
\hline \multicolumn{9}{|c|}{ Father's age at death } \\
\hline$<=69$ & 101 & 32 & 0.95 & 0.53 & 1.70 & 0.99 & 0.54 & 1.80 \\
\hline $70-79$ & 62 & 15 & 0.72 & 0.36 & 1.46 & 0.77 & 0.37 & 1.60 \\
\hline $80+$ & 90 & 30 & 1.00 & - & - & 1.00 & - & - \\
\hline N.A. & 13 & 8 & 2.33 & 0.81 & 6.73 & 2.11 & 0.63 & 7.09 \\
\hline \multicolumn{9}{|c|}{ Mother's age at birth } \\
\hline$<35 \mathrm{yrs}$ & 196 & 71 & & & & 1.00 & - & - \\
\hline$>=35 \mathrm{yrs}$ & 64 & 13 & & & & 0.76 & 0.34 & 1.70 \\
\hline N.A. & 6 & 1 & & & & 0.52 & 0.04 & 7.34 \\
\hline \multicolumn{9}{|c|}{ Father's age at birth } \\
\hline$<40 \mathrm{yrs}$ & 168 & 57 & & & & 1.00 & - & - \\
\hline$>=40 \mathrm{yrs}$ & 96 & 26 & & & & 1.18 & 0.62 & 2.23 \\
\hline N.A. & 2 & 2 & & & & 1.79 & 0.17 & 18.80 \\
\hline \multicolumn{9}{|l|}{ Birth order } \\
\hline 1 & 61 & 26 & & & & 1.00 & - & - \\
\hline $2-3$ & 90 & 34 & & & & 0.89 & 0.47 & 1.66 \\
\hline $4-5$ & 72 & 15 & & & & 0.46 & 0.20 & 1.06 \\
\hline $6+$ & 43 & 10 & & & & 0.51 & 0.17 & 1.54 \\
\hline \multicolumn{9}{|l|}{ No. of siblings } \\
\hline$<=4$ & 71 & 24 & & & & 1.00 & - & - \\
\hline $5-6$ & 78 & 22 & & & & 1.06 & 0.52 & 2.16 \\
\hline $7-8$ & 64 & 27 & & & & 1.66 & 0.79 & 3.48 \\
\hline $9+$ & 53 & 12 & & & & 1.00 & 0.39 & 2.56 \\
\hline
\end{tabular}

${ }^{* * *} p$-value $<0.001 ;{ }^{* *} p$-value $<0.05 ;{ }^{*} p$-value $<0.1$.

Source: Our elaboration on AKeA2 survey data. 
Table 4:

Parental transmission of longevity: results of logistic regression model.

Women $(N=369)$

\begin{tabular}{|c|c|c|c|c|c|c|c|c|c|c|}
\hline \multirow[b]{2}{*}{ Characteristics: } & \multicolumn{2}{|c|}{$\begin{array}{l}\text { Survive after } \\
\text { age } 100\end{array}$} & \multicolumn{4}{|c|}{ Model 1} & \multicolumn{4}{|c|}{ Model 2} \\
\hline & $\begin{array}{c}\text { Not } \\
(n=274)\end{array}$ & $\begin{array}{c}\text { Yes } \\
(n=95)\end{array}$ & OR & & $95 \%$ & FIC & OR & & $95^{c}$ & $\% \mathrm{IC}$ \\
\hline \multicolumn{11}{|c|}{ Mother's age at death } \\
\hline$<=69$ & 96 & 20 & 0.50 & $* *$ & 0.27 & 0.94 & 0.51 & $* *$ & 0.27 & 0.96 \\
\hline $70-79$ & 72 & 22 & 0.80 & & 0.43 & 1.51 & 0.79 & & 0.42 & 1.51 \\
\hline $80+$ & 91 & 38 & 1.00 & & - & - & 1.00 & & - & - \\
\hline N.A. & 15 & 15 & 3.39 & $* *$ & 1.35 & 8.49 & 2.76 & $*$ & 0.94 & 8.08 \\
\hline \multicolumn{11}{|c|}{ Father's age at death } \\
\hline$<=69$ & 106 & 38 & 0.82 & & 0.46 & 1.45 & 0.80 & & 0.44 & 1.45 \\
\hline $70-79$ & 73 & 16 & 0.43 & $* *$ & 0.21 & 0.88 & 0.41 & $* *$ & 0.20 & 0.85 \\
\hline $80+$ & 74 & 33 & 1.00 & & - & - & 1.00 & & - & - \\
\hline N.A. & 21 & 8 & 0.44 & & 0.15 & 1.28 & 0.54 & & 0.15 & 1.94 \\
\hline \multicolumn{11}{|c|}{ Mother's age at birth } \\
\hline$<35 \mathrm{yrs}$ & 191 & 63 & & & & & 1.00 & & - & - \\
\hline$>=35 \mathrm{yrs}$ & 79 & 26 & & & & & 1.93 & & 0.92 & 4.04 \\
\hline N.A. & 4 & 6 & & & & & 2.66 & & 0.45 & 15.70 \\
\hline \multicolumn{11}{|c|}{ Father's age at birth } \\
\hline$<40 \mathrm{yrs}$ & 159 & 68 & & & & & 1.00 & & - & - \\
\hline$>=40 \mathrm{yrs}$ & 108 & 24 & & & & & 0.46 & $* *$ & 0.24 & 0.89 \\
\hline N.A. & 7 & 3 & & & & & 0.39 & & 0.05 & 2.97 \\
\hline \multicolumn{11}{|l|}{ Birth order } \\
\hline 1 & 62 & 25 & & & & & 1.00 & & - & - \\
\hline $2-3$ & 82 & 33 & & & & & 0.93 & & 0.48 & 1.79 \\
\hline $4-5$ & 66 & 17 & & & & & 0.51 & & 0.22 & 1.16 \\
\hline $6+$ & 64 & 20 & & & & & 0.65 & & 0.23 & 1.79 \\
\hline \multicolumn{11}{|l|}{ No. of siblings } \\
\hline$<=4$ & 65 & 21 & & & & & 1.00 & & - & - \\
\hline $5-6$ & 68 & 23 & & & & & 1.29 & & 0.60 & 2.77 \\
\hline $7-8$ & 85 & 31 & & & & & 1.52 & & 0.70 & 3.29 \\
\hline $9+$ & 56 & 20 & & & & & 1.38 & & 0.56 & 3.44 \\
\hline
\end{tabular}

${ }^{* * *} p$-value $<0.001 ;{ }^{* *} p$-value $<0.05 ;{ }^{*} p$-value $<0.1$.

Source: Our elaboration on AKeA2 survey data. 


\section{Discussion and conclusion}

The research questions about the association between longevity and fertility were: is there a protective effect of fertility on maternal survival at advanced ages? Have long-lived women been favoured both by a lower fertility and later childbearing?

Analysing Sardinian survey data we found no association between longevity and number of offspring, or for age at first birth. These results are not in accordance with some previous studies (Kirkwood and Rose 1991; Westendrop and Kirkwood 1998; Lycett et al. 2000). In fact, the mean number of children is very similar among women of our sample: the values are 5.1 for the younger cohort controls (1918-1923), 5.4 for centenarian women and 5.6 for dead controls. Thus, considering our historical data, the number of children could not be a predictor variable for longevity.

Nevertheless, having had the last child at advanced ages shows a protective effect on the mother's survival. Our results are consistent with other previous studies (Voland and Engel 1986, Perls et al. 1997, Doblhammer 2000; Yi and Vaupel 2004). Some studies emphasise the role of bio-genetic factors while others stress socioeconomic and cultural determinants. Doblhammer (2000) suggests that certain longevity genes may extend both the childbearing period and the longevity of individual women, and Yi and Vaupel $(2004,19)$ noted that "giving birth at advanced ages could be related to a positive effect of a late menopause", also taking into consideration the possibility of a delayed menopause being itself an additional longevity marker. However, for Doblhammer $(2000,175)$ " [a]n extended period of childbearing and childraising could be associated with healthy behaviour. For example, smoking is one of the well-established determinants of age at menopause: research shows that cigarette smoking decreases the age at menopause by one to two years (e.g. McKinlay et al. 1985). Thus, late mothers may indeed experience menopause at an age higher than that of young mothers but this could be due to healthy behaviour rather than to a lower rate of ageing." Doblhammer's study contains a long discussion of the impact of socio-economic factors.

On the same topic, Müller et al. (2002, B205) proposed another interesting explanation: "A plausible explanation is that a high level of fertility increases the chance that young offspring need to be cared for after menopause, and that the probability of their survival is likely to be linked to the presence of the mother as a care-giver. This outlines a possible pathway of how the positive association of post-menopausal longevity with fertility has evolved, essentially through enhancing the likelihood for the presence of a care-giver for late children. Thus, it is plausible that extended longevity confers a selective evolutionary advantage to women who have had children later in life". In this framework, late childbirth was considered as a longevity-assurance factor. In the Sardinian context, the care-giver hypothesis can be extended by assuming the last child as care-giver. A late-fertility mother has the possibility, not only of taking care of her last child at advanced ages but also of receiving care from her last adult young child when she becomes an oldest-old. In this way a care-giving child can guarantee the mother both a better quality of life and a prolonged life. In fact, interviewing the oldest old in the AKeA2 survey, we 
observed that the majority of centenarians lived in the last child's family, usually with their last daughter. In Sardinia, elderly people generally lived at home-only $1 \%$ of the total population of people aged 65 and over live in institutions (Istat 2004).

To sum up, taking into account the main features of the Sardinian population, the association between longevity and late fertility can be explained by a combination of both genetic factors and socio-economic and cultural determinants.

The third research question was: are parental fertility characteristics related to the longevity of their offspring? Here, two interesting results emerge from our analysis, both of them in accordance with some studies cited in our introduction (Voland and Engel 1986; Gavrilov et al. 1995; Westerdorp and Kirkwod 1998; Doblhammer 2000; Smith et al. 2002; Gavrilov and Gavrilova 1997a, 2000; Gavrilova and Gavrilov 2007, 2008). First of all, there is a negative effect of a higher paternal age on the longevity of daughters; secondly, we found a negative association between birth order and longevity for both men and women, as being a child at 4 or later in the birth order decreases the probability of becoming a centenarian, in particular for a child of intermediate birth order (4-5).

The most predominant theory explaining the effects of higher paternal age in female offspring is based on gene mutation being possibly X-linked. In particular, it was established that the mutation rate in human paternal germ cells is much higher than maternal ones, with the age of the father demonstrated as being the main factor determining the spontaneous mutation rate of nuclear DNA (Crow 1997). Since the $\mathrm{X}$ chromosome is inherited by daughters rather than sons, it could explain the gender-specific life span shortening for daughters born to an older father (Gavrilov and Gavrilova 2000).

Concerning the birth order effect, a Swedish study (Modin 2002) found a U-shaped dependence of survival chances as a function of birth order with first- and very late-borns having approximately the same mortality risk, whereas individuals with intermediate birth orders (3-6) had the highest risk of death at an earlier adult age. Although we did not detect a similar U-shaped association, our results on parental transmission of longevity (Table 2) have shown that the intermediate birth orders have a significantly lower probability of surviving to age 100 while no significant differences between higher and lower birth orders were found. Modin suggests a different explanation for this, but he focuses on the idea that the effects of birth order on human mortality and survival are qualitatively different in different age groups, which adds to the complexity of this problem (Modin 2002). The main literature, in fact, finds that first-born children are more likely to become centenarians, but the mechanism of this birth order effect still remains unclear. Gavrilova and Gavrilov $(2007,63)$ suggested that it is the young age of the mother that explains the birth order effect. "For example, if the best (most vigorous) maternal ova cells are used first, for the very early pregnancies, this could explain why particularly young mothers produce particularly longevous children. This hypothesis is supported by observations that the first ovocytes to have ceased proliferation and entered meiosis are the first to ovulate in the young woman. [...]" or, an alternative hypothesis, "It may be reasonable to assume that some particularly young women may be 
initially free of many diseases and latent infections interfering with optimal foetus development [...]". Of course, there is nothing in our study that allows us to suggest a hypothesis confirming or complementing those by other authors. Nevertheless, an interesting consideration can be made. In fact, reading together the results for the first two research questions, we can conclude that, with reference to the AKeA2 study, longevous women seem to have been favoured not only by their late fertility, but also by young paternal age at the moment of their own procreation.

The last research question was: do maternal and paternal longevity favour the longer survival of their offspring?

Extreme longevity in a centenarian's family history supports the heritability of oldest-old longevity (Perls et al. 2000). This would imply increased homogeneity among the oldest old and could depend on shared genetic factors. Indeed, recent findings indicate that there is increased homozygosity at loci involved in human longevity, suggesting two copies of the same allele may favour survival at later ages (Bonafé et al. 1999; Bonafé et al. 2002), this phenomenon probably being more frequent in consanguineous individuals, assuming that such alleles are recessive (Caselli et al. 2006).

Bio-genetic studies on Sardinian centenarians have focused on some genetic factors, such as HLA polymorphisms (Caruso et al. 2000, 2001; Invidia et al. 2010), HLA haplotypes, as well as maternally inherited mitochondrial DNA variants, which contribute substantially to explaining parental transmission of longevity for centenarian women (Carru et al. 2003; Santoro et al. 2006; Raule et al. 2007; Rose et al. 2007; Capri et al. 2008; Rose et al. 2010). The familial heritability has also been pointed out in a previous demographic study based on Sardinian centenarian genealogies (Caselli et al. 2006).

In our study, we found gender-dependent effects in the inheritance of longevity as reported in the main genetic/gerontological/demographic literature (see also a long discussion in Cournil et al. 2000). In fact, for Sardinian women the transmission is found along both the maternal and paternal line while for men there is no relation between their own longevity and their parents' longevity.

Of course, parents transmit not only their genes to their children, but also ways of behaving and habits of life, particularly as regards alimentation, and these have an effect on their health during their lives, and so on their age at death too. Might this effect be gender-dependent? It is possible. In Sardinia the women of past generations, who were not involved in extra-domestic activities, were closely tied to the cultural and alimentary traditions of their family of origin - traditions that they maintained even after marriage, transferring them to their conjugal family. The men, by contrast, assumed new roles and life styles connected with their working activity when they left their family of origin, and also adopted new alimentary habits from their acquired family. It is therefore probable that, for the men, much of the 'memory' of the behavioural determinants (alimentary tradition and life style) of longevity in the family of origin was cancelled in the course of their life, while the (positive and negative) effects of their new family context prevailed. 


\section{References}

Abbott, M. H., H. Abbey, D. R. Bolling, and E. A. Murphy. 1978. "The Familial Component in Longevity: A Study of Offspring of Nonagenarians III. Intrafamilial Studies". American Journal of Medical Genetics 2 (2): 105-120.

Abbott, M. H., E. A. Murphy, D. R. Bolling, and H. Abbey. 1974. "The Familial Component in Longevity: A Study of Offspring of Nonagenarians II. Preliminary Analysis of the Completed Study". The Johns Hopkins Medical Journal 134 (1): $1-16$.

Astolfi, P., G. Caselli, O. Fiorani, R. M. Lipsi, A. Lisa, and S. Tentoni. 2009. "Late Reproduction Behaviour in Sardinia: Spatial Analysis Suggests Local Aptitude Towards Reproductive Longevity". Evolution and Human Behavior 30 (2): 93-102. doi:10.1016/j . evol humbehav .2008.09.001.

Astolfi, P., L. Ulizzi, and L. A. Zonta. 2002. "Trends in Childbearing and Stillbirth Risk: Heterogeneity Among Italian Regions”. Human Biology 74 (2): 185-196.

Behr, M. A., and P. M. Small. 1997. "Middle-Age Mothers Live Longer". Nature 389: 133-134.

Bocquet-Appel, J.-P., and L. Jakobi. 1990. "Familial Transmission of Longevity". Annals of Human Biology 17 (2): 81-95. doi:10 . 1080/03014469000000832.

Bonafè, M., F. Marchegiani, M. Cardelli, F. Olivieri, L. Cavallone, S. Giovagnetti, C. Pieri, M. Marra, R. Antonicelli, L. Troiano, P. Gueresi, G. Passeri, M. Berardelli, G. Paolisso, M. Barbieri, S. Tesei, R. Lisa, G. De Benedictis, and C. Franceschi. 2002. "Genetic Analysis of Paraoxonase (PON1) Locus Reveals an Increased Frequency of Arg192 Allele in Centenarians". European Journal of Human Genetics 10 (5): 292-296. doi:10.1038/sj . ejhg. 5200806.

Bonafè, M., F. Olivieri, D. Mari, G. Baggio, R. Mattace, M. Berardelli, P. Sansoni, G. De Benedictis, M. De Luca, F. Marchegiani, L. Cavallone, M. Cardelli, S. Giovagnetti, L. Ferrucci, L. Amadio, R. Lisa, M. G. Tucci, L. Troiano, G. Pini, P. Gueresi, M. Morellini, S. Sorbi, G. Passeri, C. Barbi, S. Valensin, D. Monti, L. Deiana, G. M. Pes, C. Carru, and C. Franceschi. 1999. "P53 Codon 72 Polymorphism and Longevity: Additional Data on Centenarians From Continental Italy and Sardinia". American Journal of Human Genetics 65 (6): 1782-1785. doi:10.1086/302664.

Caglià, A., A. Novelletto, M. Dobosz, P. Malaspina, B. M. Ciminelli, and V. L. Pascali. 1997. "Y-Chromosome STR Loci in Sardinia and Continental Italy Reveal IslanderSpecific Haplotypes". European Journal of Human Genetics 5 (5): 288-292.

Capri, M., S. Salvioli, D. Monti, C. Caruso, G. Candore, S. Vasto, F. Olivieri, F. Marchegiani, P. Sansoni, G. Baggio, D. Mari, G. Passarino, G. De Benedictis, and C. Franceschi. 2008. "Human Longevity Within an Evolutionary Perspective: The Peculiar Paradigm of a Post-Reproductive Genetics". Experimental Gerontology 43 (2): 53-60. doi:10.1016/j . exger.2007.06.004. 
Carru, C., G. M. Pes, L. Deiana, G. Baggio, C. Franceschi, D. Lio, C. R. Balistreri, G. Candore, G. Colonna-Romano, and C. Caruso. 2003. "Association Between the HFE Mutations and Longevity: A Study in Sardinian Population". Mechanisms of Ageing and Development 124 (4): 529-532.

Caruso, C., G. Candore, G. Colonna Romano, D. Lio, M. Bonafè, S. Valensin, and C. Franceschi. 2000. "HLA, Aging, and Longevity: A Critical Reappraisal". Human Immunology 61 (9): 942-949.

Caruso, C., G. Candore, G. C. Romano, D. Lio, M. Bonafè, S. Valensin, and C. Franceschi. 2001. "Immunogenetics of Longevity. Is Major Histocompatibility Complex Polymorphism Relevant to the Control of Human Longevity? A Review of Literature Data". Mechanisms of Ageing and Development 122 (5): 445-462.

Caselli, G., and R. M. Lipsi. 2006. "Survival Differences Among the Oldest Old in Sardinia: Who, What, Where, and Why?" Demographic Research 14 (13): 267-294. doi:10.4054/DemRes. 2006.14.13.

Caselli, G., L. Pozzi, J. W. Vaupel, L. Deiana, G. Pes, C. Carru, C. Franceschi, and G. Baggio. 2006. "Family Clustering in Sardinian Longevity: A Genealogical Approach". Experimental Gerontology 41 (8): 727-736. doi:10 . 1016/j . exger . 2006.05 .009$.

Cavalli-Sforza, L. L., P. Menozzi, and A. Piazza. 1994. The History and Geography of Human Genes. Princeton, N.J.: Princeton University Press.

Charlesworth, D., and B. Charlesworth. 1980. "Sex Differences in Fitness and Selection for Centric Fusions Between Sex-Chromosomes and Autosomes". Genetical Research 35 (2): 205-214. doi:10. 1017/S0016672300014051.

Christensen, K., T. E. Johnson, and J. W. Vaupel. 2006. "The Quest for Genetic Determinants of Human Longevity: Challenges and Insights". Nature Reviews Genetics 7 (6): 436-448. doi:10.1038/nrg1871.

Cooper, G. S., and D. P. Sandler. 1998. "Age at Natural Menopause and Mortality". Annals of Epidemiology 8 (4): 229-235.

Cournil, A., J. Legay, and F. Schächter. 2000. "Evidence of Sex-Linked Effects on the Inheritance of Human Longevity: A Population-Based Study in the Valserine Valley (French Jura), 18-20th Centuries". Proceedings of the Royal Society of London. Series B: Biological Sciences 267 (1447): 1021-1025. doi:10 . 1098 / rspb. 2000.1105.

Crawford, M. H., and L. Rogers. 1982. "Population Genetic Models in the Study of Aging and Longevity in a Mennonite Community". Social Science $\mathcal{E}$ Medicine 16 (2): 149-153.

Crow, J. F. 1997. "The High Spontaneous Mutation Rate: Is It a Health Risk?" Proceedings of the National Academy of Sciences 94 (16): 8380-8386. 
Deiana, L., L. Ferrucci, G. M. Pes, C. Carru, G. Delitala, A. Ganau, S. Mariotti, A. Nieddu, S. Pettinato, P. Putzu, C. Franceschi, and G. Baggio. 1999. "AKEntAnnos The Sardinia Study of Extreme Longevity". Aging, Clinical and Experimental Research 11 (3): 142-149.

Desjardins, B., and H. Charbonneau. 1990. "L'héritabilité de la longévité". Population 45 (3): 603-616.

Doblhammer, G., and J. W. Vaupel. 1999. Reproductive History and Mortality Later in Life for Austrian Women. Tech. rep. WP-1999-012. Rostock: Max Planck Institute for Demographic Research.

Doblhammer, G. 2000. "Reproductive History and Mortality Later in Life: A Comparative Study of England and Wales and Austria". Population Studies 54 (2): 169-176. doi:10. $1080 / 713779087$.

Doblhammer, G., and J. Oeppen. 2003. "Reproduction and Longevity Among the British Peerage: The Effect of Frailty and Health Selection". Proceedings of the Royal Society. Series B: Biological Sciences 270 (1524): 1541-1547. doi:10 . $1098 / \mathrm{rspb} .2003 .2400$.

Gavrilov, L. A., and N. S. Gavrilova. 1997a. "Parental Age at Conception and Offspring Longevity". Reviews in Clinical Gerontology 7: 5-12.

Gavrilov, L. A., and N. S. Gavrilova. 1997b. "When Fatherhood Should Stop?" Science 277 (5322): 17-21.

Gavrilov, L. A., and N. S. Gavrilova. 2001. "Human Longevity and Parental Age at Conception". In Sex and Longevity: Sexuality, Gender, Reproduction, Parenthood, ed. by J.-M. Robine, T. B. L. Kirkwood, and M. Allard, 7-31. Research and Perspectives in Longevity. Berlin, Heidelberg: Springer.

Gavrilov, L. A., N. S. Gavrilova, N. P. Snarskaya, V. G. Semyonova, G. N. Evdokushkina, A. L. Gavrilova, E. V. Lapshin, and N. N. Evdokushkina. 1995. "Paternal Age and the Life Span of Descendants". Doklady Biological Sciences 341: 196-198.

Gavrilova, N. S., and L. A. Gavrilov. 2002. Mechanism of Inheritance of Human Longevity: Paradox Resolved. Poster at the Annual meeting of the Gerontological Society of America, November 22-26, Boston.

Gavrilova, N. S., and L. A. Gavrilov. 2007. "Search for Predictors of Exceptional Human Longevity: Using Computerized Genealogies and Internet Resources for Human Longevity Studies". North American Actuarial Journal 11 (1): 49-67.

Gavrilova, N. S., and L. A. Gavrilov. 2008. "Effects of Parental Longevity on Mortality Trajectories in Human Offspring". Gerontologist 48: 494.

Golini, A. 1967. Aspetti demografici della Sardegna, quaderni del seminario di scienze politiche dell'universitä degli studi di Cagliari. Milano: Giuffrè Editore.

Grundy, E., and C. Tomassini. 2005. "Fertility History and Health in Later Life: A Record Linkage Study in England and Wales". Social Science $\mathcal{E}$ Medicine 61 (1): 217-228. doi:10.1016/j . socscimed.2004 .11.046. 
Hamilton, W. D. 1966. "The Moulding of Senescence by Natural Selection". Journal of Theoretical Biology 12 (1): 12-45.

Harrell, F. E. 2001. Regression Modeling Strategies. With Applications to Linear Models, Logistic Regression, and Survival Analysis. New York: Springer.

Herskind, A. M., M. McGue, N. V. Holm, T. I. A. Sørensen, B. Harvald, and J. W. Vaupel. 1996. "The Heritability of Human Longevity: A Population-Based Study of 2872 Danish Twin Pairs Born 1870-1900". Human Genetics 97 (3): 319-323. doi:10.1007/BF02185763.

Iachine, I. A., N. V. Holm, J. R. Harris, A. Z. Begun, M. K. Iachina, M. Laitinen, J. Kaprio, and A. I. Yashin. 1998. "How Heritable Is Individual Susceptibility to Death? The Results of an Analysis of Survival Data on Danish, Swedish and Finnish Twins". Twin Research 1 (4): 196-205. doi:10 . 1375 / 136905298320566168.

Invidia, L., S. Salvioli, S. Altilia, M. Pierini, M. P. Panourgia, D. Monti, F. De Rango, G. Passarino, and C. Franceschi. 2010. "The Frequency of Klotho KL-VS Polymorphism in a Large Italian Population, From Young Subjects to Centenarians, Suggests the Presence of Specific Time Windows for Its Effect". Biogerontology 11 (1): 67-73. doi:10.1007/s10522-009-9229-z.

Istat. 2004. $14^{\circ}$ censimento generale della popolazione e delle abitazioni - 21 Ottobre 2001. Tech. rep. National Statistical Institute of Italy. http://dawinci . istat. it/.

Jung, A., H.-C. Schuppe, and W.-B. Schill. 2003. "Are Children of Older Fathers at Risk for Genetic Disorders?" Andrologia 35 (4): 191-199. doi:10. 1046/j . 1439$0272.2003 .00579 . \mathrm{x}$.

Kirkwood, T. B. L., and M. R. Rose. 1991. "Evolution of Senescence: Late Survival Sacrificed for Reproduction". Philosophical Transactions of the Royal Society of London. Series B: Biological Sciences 332 (1262): 15-24. doi:10. 1098/rstb . 1991.0028.

Larke, A., and D. E. Crews. 2006. "Parental Investment, Late Reproduction, and Increased Reserve Capacity Are Associated With Longevity in Humans". Journal of Physiological Anthropology 25 (1): 119-131. doi:10.2114/jpa2 .25. 119.

Lipsi, R. M., G. Caselli, L. Pozzi, G. Baggio, C. Carru, C. Franceschi, J. W. Vaupel, and L. Deiana. 2014. "Demographic Characteristics of Sardinian Centenarian Genealogies: Methodology and Preliminary Results of the AKeA2 Study". (submitted revised paper), Demographic Research.

Livi Bacci, M. 1977. A History of Italian Fertility During the Last Two Centuries. Princeton, N.J.: Princeton University Press.

Lycett, J. E., R. I. Dunbar, and E. Voland. 2000. "Longevity and the Costs of Reproduction in a Historical Human Population". Proceedings of the Royal Society. Series B: Biological Sciences 267 (1438): 31-35. 
McArdle, P. F., T. I. Pollin, J. R. O'Connell, J. D. Sorkin, R. Agarwala, A. A. Schäffer, E. A. Streeten, T. M. King, A. R. Shuldiner, and B. D. Mitchell. 2006. "Does Having Children Extend Life Span? A Genealogical Study of Parity and Longevity in the Amish". The Journals of Gerontology. Series A: Biological Sciences and Medical Sciences 61 (2): 190-195.

McKinlay, S. M., N. L. Bifano, and J. B. McKinlay. 1985. "Smoking and Age at Menopause in Women". Annals of Internal Medicine 103 (3): 350-356.

Modiano, G., L. Terrenato, R. Scozzari, S. A. Santachiara-Benerecetti, L. Ulizzi, C. Santolamazza, R. Petrucci, and P. Santolamazza. 1986. "Population Genetics in Sardinia: With a Historical Account on the Birth of the Haldane "Malaria Hypothesis"”. Atti della Accademia Nazionale dei Lincei (Roma) 18: 257-330.

Modin, B. 2002. "Birth Order and Mortality: A Life-Long Follow-Up of 14,200 Boys and Girls Born in Early 20th Century Sweden". Social Science $\mathcal{E}$ Medicine 54 (7): 1051-1064. doi:10.1016/S0277-9536(01)00080-6.

Müller, H.-G., J.-M. Chiou, J. R. Carey, and J.-L. Wang. 2002. "Fertility and Life Span: Late Children Enhance Female Longevity". The Journals of Gerontology. Series A: Biological Sciences and Medical Sciences 57 (5): B202-206.

Pearl, R. 1931. "Studies on Human Longevity IV: The Inheritance of Longevity. Preliminary Report". Human Biology 3: 245-269.

Perls, T. T., L. Alpert, and R. C. Fretts. 1997. "Middle-Aged Mothers Live Longer". Nature 389 (6647): 133-134. doi:10.1038/38148.

Perls, T. T., M. Shea-Drinkwater, J. Bowen-Flynn, S. B. Ridge, S. Kang, E. Joyce, M. Daly, S. J. Brewster, L. Kunkel, and A. A. Puca. 2000. "Exceptional Familial Clustering for Extreme Longevity in Humans". Journal of the American Geriatrics Society 48 (11): 1483-1485.

Perls, T. T., and D. Terry. 2003. "Genetics of Exceptional Longevity". Experimental Gerontology 38 (7): 725-730. doi:10 . 1016/S0531-5565(03)00098-6.

Pes, G. M., D. Lio, C. Carru, L. Deiana, G. Baggio, C. Franceschi, L. Ferrucci, F. Oliveri, L. Scola, A. Crivello, G. Candore, G. Colonna-Romano, and C. Caruso. 2004. "Association Between Longevity and Cytokine Gene Polymorphisms: A Study in Sardinian Centenarians". Aging Clinical and Experimental Research 16 (3): 244-248.

Philippe, P. 1978. "Familial Correlations of Longevity: An Isolate-Based Study". American Journal of Medical Genetics 2 (2): 121-129. doi:10 . 1002 / ajmg . 1320020203.

Poulain, M., G. M. Pes, C. Grasland, C. Carru, L. Ferrucci, G. Baggio, C. Franceschi, and L. Deiana. 2004. "Identification of a Geographic Area Characterized by Extreme Longevity in the Sardinia Island: The AKEA Study". Experimental Gerontology 39 (9): 1423-1429. doi:10.1016/j . exger . 2004 .06 .016. 
Raule, N., F. Sevini, A. Santoro, S. Altilia, and C. Franceschi. 2007. "Association Studies on Human Mitochondrial DNA: Methodological Aspects and Results in the Most Common Age-Related Diseases". Mitochondrion 7 (1-2): 29-38. doi:10.1016/j .mito.2006.11.013.

Robine, J.-M., A. Cournil, N. Henon, and M. Allard. 2003. "Have Centenarians Had Younger Parents Than the Others?" Experimental Gerontology 38 (4): 361-365.

Rose, G., G. Passarino, V. Scornaienchi, G. Romeo, S. Dato, D. Bellizzi, V. Mari, E. Feraco, R. Maletta, A. Bruni, C. Franceschi, and G. De Benedictis. 2007. "The Mitochondrial DNA Control Region Shows Genetically Correlated Levels of Heteroplasmy in Leukocytes of Centenarians and Their Offspring". BMC Genomics 29 (8): 293. doi:10. 1186/1471-2164-8-293.

Rose, G., G. Romeo, S. Dato, P. Crocco, A. C. Bruni, A. Hervonen, K. Majamaa, F. Sevini, C. Franceschi, and G. Passarino. 2010. "Somatic Point Mutations in mtDNA Control Region Are Influenced by Genetic Background and Associated With Healthy Aging: A GEHA Study". PLoS ONE 5 (10): e13395. doi:10.1371/ journal . pone.0013395.

Santoro, A., S. Salvioli, N. Raule, M. Capri, F. Sevini, S. Valensin, D. Monti, D. Bellizzi, G. Passarino, G. Rose, G. De Benedictis, and C. Franceschi. 2006. "Mitochondrial DNA Involvement in Human Longevity". Biochimica Et Biophysica Acta - Bioenergetics 1757 (9-10): 1388-1399. doi:10 . 1016/j . bbabio . 2006. 05.040.

Smith, K. R., G. P. Mineau, and C. Sahm. 2007. Paternal Age and Maternal Age and Their Effects on Adult Offspring Mortality. Manuscript not published.

Smith, K. R., G. P. Mineau, and L. L. Bean. 2002. "Fertility and Post-Reproductivity Longevity". Biodemography and Social Biology 49 (3-4): 185-205.

Snowdon, D. A., R. L. Kane, W. L. Beeson, G. L. Burke, J. M. Sprafka, J. Potter, H. Iso, D. R. J. Jacobs, and R. L. Phillips. 1989. "Is Early Natural Menopause a Biologic Marker of Health and Aging?" American Journal of Public Health 79 (6): 709-714.

Sorkin, J., W. Post, T. I. Pollin, J. R. O'Connell, B. D. Mitchell, and A. R. Shuldiner. 2005. "Exploring the Genetics of Longevity in the Old Order Amish". Mechanisms of Ageing and Development 126 (2): 347-350. doi:10 . 1016/j . mad. 2004.08 . Q27.

Vaupel, J. W., J. R. Carey, K. Christensen, T. E. Johnson, A. I. Yashin, N. V. Holm, I. A. Iachine, V. Kannisto, A. A. Khazaeli, P. Liedo, V. D. Longo, Y. Zeng, K. G. Manton, and J. W. Curtsinger. 1998. "Biodemographic Trajectories of Longevity". Science 280 (5365): 855-860. doi:10 . 1126/science. 280 . 5365. 855.

Vinogradov, A. E. 1998. "Male Reproductive Strategy and Decreased Longevity". Acta Biotheoretica 46 (2): 157-160. doi:10.1023/A: 1001181921303. 
Voland, E., and C. Engel. 1986. "Ist das postmenopausale Sterbealter Variable einer fitnessmaximierenden Reproduktionsstrategie?" Anthropologischer Anzeiger 44 (1): 19-34.

Westendorp, R. G. J., and T. B. Kirkwood. 1998. "Human Longevity at the Cost of Reproductive Success". Nature 396 (6713): 743-746. doi:10. 1038/25519.

Westendorp, R. G. J., and T. B. L. Kirkwood. 2001. "Maternal and Paternal Lines of Familial Longevity". Population (English Edition) 13 (1): 223-235.

Yi, Z., and J. W. Vaupel. 2004. "Association of Late Childbearing With Healthy Longevity Among the Oldest-Old in China". Population Studies 58 (1): 37-53. doi:10.1080/0032472032000175437.

Zei, G., A. Lisa, and P. Astolfi. 1990. "Fertility and Malaria in Sardinia". Annals of Human Biology 17 (4): 315-330. doi:10. 1080/03014469000001092.

Zei, G., A. Lisa, O. Fiorani, C. Magri, L. Quintana-Murci, O. Semino, and A. S. Santachiara-Benerecetti. 2003. "From Surnames to the History of Y Chromosomes: The Sardinian Population as a Paradigm". European Journal of Human Genetics 11 (10): 802-807. doi:10.1038/sj . ejhg . 5201040.

Zei, G., A. Piazza, A. Moroni, and L. L. Cavalli-Sforza. 1986. "Surnames in Sardinia III: the Spatial Distribution of Surnames for Testing Neutrality of Genes". Annals of Human Genetics 50 (2): 169-180. doi:10.1111/j . 1469-1809 . 1986. tb01036. $\mathrm{x}$. 